\title{
DISPONIBILIDADE HÍDRICA DO SOLO E PRODUTIVIDADE DO EUCALIPTO EM TRÊS REGIÕES DA BACIA DO RIO DOCE ${ }^{1}$
}

\author{
Maria José Hatem de Souza ${ }^{2}$, Aristides Ribeiro ${ }^{3}$, Hélio Garcia Leite ${ }^{4}$, Fernando Palha Leite ${ }^{5}$ Rosandro \\ Boligon Minuzzi ${ }^{6}$
}

\begin{abstract}
RESUMO - Analisou-se a produtividade de povoamentos de eucalipto, localizados nas regiões Belo Oriente, Nova Era e Guanhães, situadas na Bacia do Rio Doce, em Minas Gerais. Estudaram-se as precipitações ocorridas nas estações chuvosas e os componentes do balanço hídrico de Thornthwaite e Mather (1955), relativos ao período de janeiro de 1985 a dezembro de 1998, objetivando estudar a influência desses componentes com o ganho de volume médio anual de madeira $\left(\mathrm{m}^{3} \mathrm{ha}^{-1}\right)$. Para tal, utilizaram-se dados do inventário florestal da Empresa Florestal Celulose Nipo-Brasileira-CENIBRA, relativos à idade de três a sete anos. A produtividade de madeira foi influenciada pelo total precipitado na estação chuvosa (PEC). Os menores valores de incremento periódico mensal (IPM) foram observados nos anos precedidos de estação chuvosa seca (S) ou muito seca (MS), sendo que os maiores valores de IPM ocorreram nos anos precedidos de estações chuvosas, classificadas como chuvosa (C) ou muito chuvosa (MC). Considerando que tal fato foi mais pronunciado em Guanhães e Nova Era, verificou-se a correlação da PEC, finalizada em cada ano, com o IPM nos períodos de aumento (1986 a 1992) e diminuição na PEC (1992 a 1995), sendo que essas correlações atingiram um $\mathrm{r}^{2}$ superior a $80 \%$. Para um aumento de $100 \mathrm{~mm}$ na PEC de um ano para outro, o aumento no IPM foi, em média, de $0,445 \mathrm{~m}^{3} \mathrm{ha}^{-1} \mathrm{mês}^{-1}$, enquanto para uma redução de $100 \mathrm{~mm}$ a diminuição no IPM foi de $0,64 \mathrm{~m}^{3} \mathrm{ha}^{-1} \mathrm{mês}^{-1}$, para as duas regiões. Guanhães apresenta o maior índice de local médio, assim como a maior produtividade média, seguindo-se Nova Era e Belo Oriente.
\end{abstract}

Palavras-chave: Produtividade florestal, balanço hídrico seqüencial e influência climática.

\section{SOIL WATER AVAILABILITY AND EUCALYPTUS PRODUCTIVITY IN THREE REGIONS OF THE RIO DOCE BASIN}

\begin{abstract}
The productivity of eucalyptus stands found in Belo Oriente, Nova Era and Guanhães areas in the Rio Doce Basin, Minas Gerais State were analyzed. The precipitation events occurred over the rainy seasons as well as the water balance components by Thornthwaite and Mather, in 1955, relative to the period from January 1985 to December 1998 were studied, in order to determine the influence of these components on the gain of the annual average volume of wood $\left(\mathrm{m}^{3} \mathrm{ha}{ }^{-1}\right)$. To do so, the forest inventory data from the Empresa Florestal Celulose Nipo-Brasileira-CENIBRA, relative to the 3 - 7 year age range, were used. Wood productivity was affected by the total precipitation in the rainy season (PEC). The lowest values of the monthly periodic increment (IPM) were observed in those years preceded by dry (S) or very dry rainy
\end{abstract}

\footnotetext{
${ }^{1}$ Recebido em 05.10.2004 e aceito para publicação em 05.04.2006.

${ }^{2}$ Departamento de Agronomia da Universidade Federal dos Vales do Jequitinhonha e Mucuri, UFVJM, 39100-000 Diamantina-MG.E-mail: <mariahatem@yahoo.com.br>.<mjhatem@ufv.br>.

${ }^{3}$ Departamento de Engenharia Agrícola da UFV, 36 570-000 Viçosa-MG. E-mail: <ribeiro@ufv.br>.

${ }^{4}$ Departamento de Engenharia Florestal da UFV. E-mail: <hgleite@ufv.br>.

${ }^{5}$ Empresa Celulose Nipo-Brasileira S. A. - CENIBRA. E-mail: <fernando.leite@ cenibra.com.br>.

${ }^{6}$ Programa de Pós-Graduação em Engenharia Agrícola da UFV. E-mail: <megadetheoro@ bol.com.br>.
} 
season (MS), whereas the highest IPM values occurred in those years preceded by rainy season so-classified as rainy $(C)$ or very rainy $(M C)$. Taking into account that this fact was more pronounced in both Guanhães and Nova Era, the correlation between PEC finished at every year and IPM for either the increase (1986 to 1992) and decrease periods (1992 to 1995) in PEC were verified; these correlations reached a $r^{2}$ above $80 \%$. For a $100 \mathrm{~mm}$ increase in PEC from a year to another, the increase in IPM averaged $0.445 \mathrm{~m}^{3} \mathrm{ha}$ ${ }^{I} \mathrm{mo}^{-1}$, whereas for a reduction of $100 \mathrm{~mm}$ the decrease in IPM was $0.64 \mathrm{~m}^{3} \mathrm{ha}^{-1} \mathrm{mo}^{-1}$ for both regions. Guanhães showed the highest average site index as well as the highest average productivity, following the Nova Era and Belo Oriente regions.

Keywords: Forest productivity, sequential hydric balance and climate influence.

\section{INTRODUÇÃO}

A influência climática no crescimento das árvores tem sido estudada por vários autores (WOOLLONS et al., 1997; BERGH et al., 1998; WENSEL e TURNBLOM, 1998 e YET, 1997, citados por YET, 2000; SOARES, 1999; MAESTRI, 2003). Os principais elementos climáticos que afetam o crescimento das árvores são: radiação solar, temperatura e disponibilidade hídrica. A radiação solar constitui a fonte primária de energia para o processo fotossintético (PIRES O'BRIEN, 1995). A temperatura influencia os processos fisiológicos, como fotossíntese, respiração, transpiração e divisão celular; enquanto a água é fundamental a todos os processos fisiológicos e bioquímicos (CAMPOS, 1970; PEREIRA et al., 2002). Portanto, os desenvolvimentos dos plantios florestais apresentam forte dependência das disponibilidades hídricas e energéticas do meio ambiente.

Maestri (2003), estudando a influência das variáveis ambientais no incremento corrente anual em altura dominante de povoamentos de Eucalyptus grandis, concluiu que as variáveis mais significativas foram a precipitação pluviométrica, evapotranspiração potencial, temperatura máxima e temperatura mínima. Stape (2002) concluiu que o aporte hídrico foi o principal elemento controlador da produtividade do eucalipto (clone de Eucalyptus grandis $x$ Eucalyptus uroplhylla) e do uso de recursos naturais, assim como, em períodos de déficit hídrico, a produção de madeira é significativamente afetada.

A relação entre a disponibilidade hídrica e a produtividade florestal é concernente aos efeitos diretos e indiretos da deficiência de água no crescimento das árvores. Dentre esses efeitos, destacam-se: diminuição da taxa fotossintética, em razão do aumento na resistência estomática (VOSE e SWANK, 1994); diminuição do aporte nutricional às árvores, via fluxo de massa e difusão; diminuição na velocidade de mineralização da matéria orgânica; e em grau mais elevado de deficiência hídrica, o próprio colapso funcional em níveis citoplasmático e tissular (SANDS e MULLIGAN, 1990).

A disponibilidade hídrica dos solos é influenciada pelas condições térmicas e pela distribuição espaçotemporal das precipitações. No balanço hídrico, desenvolvido por Thornthwaite e Mather (1955), a taxa evapotranspirativa está diretamente relacionada à temperatura. $\mathrm{O}$ balanço hídrico pode ser entendido como a contabilização dos ganhos e perdas de água, em determinado volume de solo. Os ganhos são constituídos, basicamente, pela precipitação pluvial, enquanto as perdas são provenientes de evapotranspiração, percolação profunda e escoamentos superficial e subsuperficial de saída. O volume de solo é definido pela profundidade efetiva do sistema radicular, onde se observa a absorção de água pelas raízes.

Baseado no exposto, o presente trabalho foi desenvolvido objetivando a análise comparativa da produtividade de povoamentos de eucalipto (E. grandis), localizados em três regiões apresentando características climáticas distintas, na Bacia do Rio Doce. Procurouse explicar a variação de produtividade entre as localidades estudadas, analisando-se os componentes do balanço hídrico.

\section{MATERIAL E MÉTODOS}

Os dados de temperatura média e precipitação relativos a Guanhães, Nova Era e Belo Oriente foram fornecidos pela Empresa Florestal Celulose Nipo-Brasileira - CENIBRA, sendo obtidos em estações meteorológicas convencionais. Essas regiões estão esquematizadas na Figura 1. 

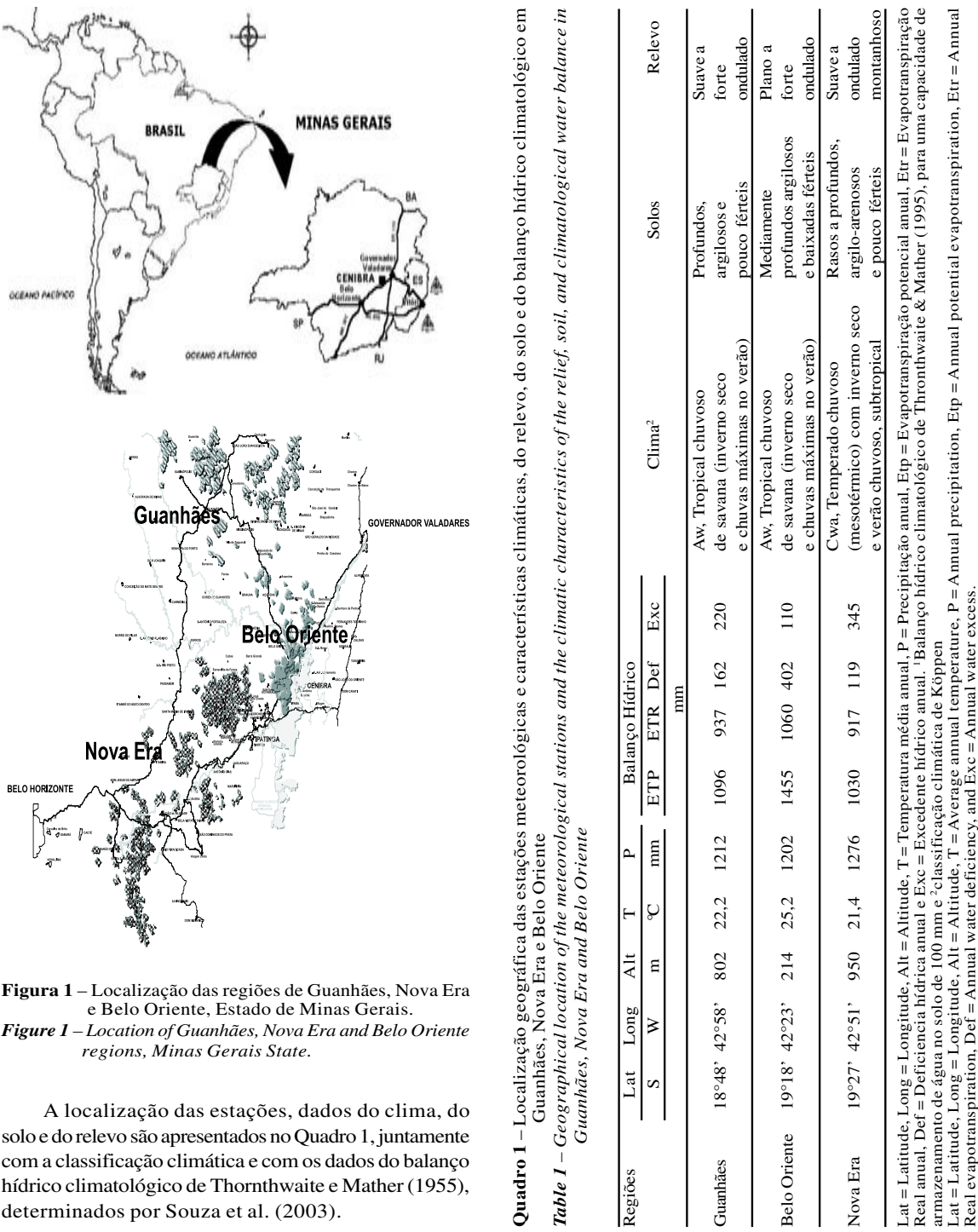

Figura 1 - Localização das regiões de Guanhães, Nova Era Belo Oriente, Estado de Minas Gerais.

Figure 1-Location of Guanhães, Nova Era and Belo Oriente regions, Minas Gerais State.

A localização das estações, dados do clima, do solo e do relevo são apresentados no Quadro 1, juntamente com a classificação climática e com os dados do balanço hídrico climatológico de Thornthwaite e Mather (1955), determinados por Souza et al. (2003). 
O balanço hídrico mensal entre janeiro de 1985 e dezembro de 1998 (Figura 2) foi calculado com o intuito de fazer uma comparação do ponto de vista hídrico entre as três regiões da bacia do rio Doce. Para tal, utilizou-se da metodologia proposta por Thornthwaite e Mather (1955) para uma capacidade de armazenamento do solo (CAD) de $200 \mathrm{~mm}$. Empregou-se esse valor por estar entre a faixa encontrada na literatura. Segundo Pereira et al. (2002), em espécies florestais a CAD varia de 150 a 300 mm. Stape e Gomes (1996) utilizaram uma CAD de $200 \mathrm{~mm}$ para contabilização do balanço hídrico de Thornthwaite e Mather (1955) em plantios de eucalipto (E. grandis $x$ urophylla), com idade variando de três a oito anos. Neves (2000) determinou que a CAD para plantios de eucalipto, no litoral do Espírito Santo, com árvores com nove anos, foi de $168 \mathrm{~mm}$. Por sua vez, Sacramento Neto (2001), trabalhando com plantios jovens de eucalipto ( 1 e 2 anos) na região de Belo Oriente, na bacia do rio Doce, determinou que em solos de baixada a CAD variou de 137 a $171 \mathrm{~mm}$, e, em solos de encosta, essa variação foi de 70 a $110 \mathrm{~mm}$. Foram calculados os componentes do balanço hídrico, bem como a evapotranspiração relativa (ETR/ETP), que é a razão entre a evapotranspiração real e a potencial (DOORENBOS e KASSAM, 1979) (Figura 2).

Os períodos chuvosos foram avaliados empregandose a técnica dos quantis, metodologia desenvolvida por Pinkayan (1966). Para isso, utilizaram-se os dados de precipitação referentes ao semestre mais chuvoso, denominado e estação chuvosa. O período da estação chuvosa foi classificado, segundo Xavier (2001), como: muito seco (MS), seco (S), normal (N), chuvoso (C) e muito chuvoso (MC). Para tal, foram usados os quantis $\mathrm{Q}(0,15), \mathrm{Q}(0,35), \mathrm{Q}(0,65)$ e $\mathrm{Q}(0,85)$, respectivamente, como limites para tais classificações.

A metodologia dos quantis para estudos de precipitação agrupa, geralmente, os períodos de maior ou menor ocorrência de precipitação com duração de quatro meses, denominados "quadra chuvosa". Devido às características dos locais de estudo, bem como à aplicabilidade em estudos florestais, optou-se por trabalhar com períodos de seis meses, aqui denominados estação chuvosa.

Foi quantificado o ganho de volume médio anual de madeira $\left(\mathrm{m}^{3} \mathrm{ha}^{-1}\right)$, dos plantios de eucalipto ( $E$. grandis), utilizando-se dados do inventário florestal contínuo, da Empresa Florestal Celulose Nipo-Brasileira (CENIBRA), realizado entre 1986 e 1998 nas regiões contempladas no presente estudo. Em Guanhães, trabalhou-se com 88 talhões, enquanto em Nova Era o estudo envolveu 75 talhões e em Belo Oriente, 25. A idade das árvores variou de três a sete anos. Maiores detalhes sobre os dados anuais empregados podem ser visualizados no Quadro 2.

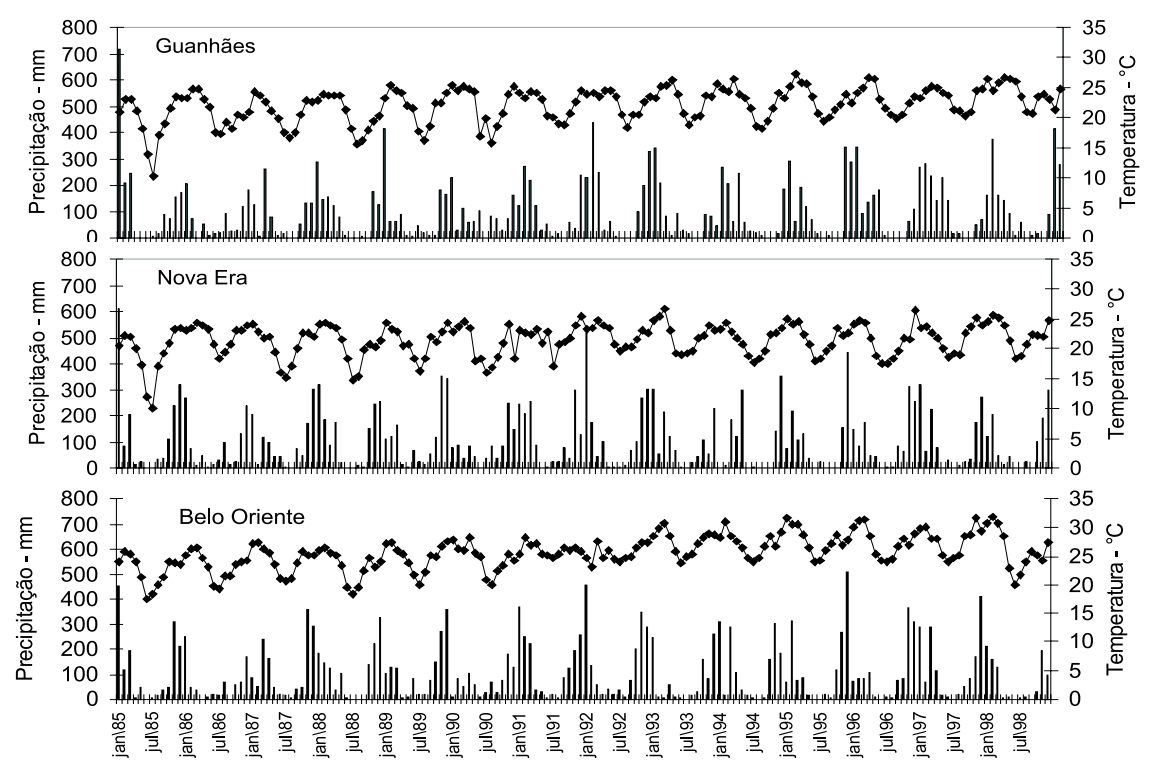

Figura 2 - Precipitação mensal e temperatura média do ar, no período de 1985 a 1998, em Guanhães, Nova Era e Belo Oriente. Figure 2-Monthly precipitation and average air temperature over the period 1985 - 1998 in Guanhães, Nova Era and Belo Oriente. 
Quadro 2 - Ano de contabilização do incremento periódico mensal (IPM), número de lotes, idade média, número de fustes por hectare, índice de sítio médio e os coeficientes de variação do IPM para cada ano, nas três localidades estudadas

Table 2 -Accounting year of the monthly periodic increment (IPM), lot numbers, average age, stem numbers by hectare, average site index and the IPM variation coefficients for each year, for the three localities under study

\begin{tabular}{|c|c|c|c|c|c|c|}
\hline \multicolumn{7}{|c|}{ Belo Oriente } \\
\hline $\begin{array}{l}\text { Ano do } \\
\text { IPM }\end{array}$ & $\begin{array}{l}\text { Número } \\
\text { de Lotes }\end{array}$ & $\begin{array}{c}\text { Idade Média/ } \\
\text { Anos }\end{array}$ & $\begin{array}{c}\text { IPM - } \\
\mathrm{m}^{3} \cdot \mathrm{ha}^{-1} \cdot \mathrm{mês}^{-1}\end{array}$ & $\begin{array}{l}\text { Fustes por } \\
\text { Hectare }\end{array}$ & $\begin{array}{c}\text { Índice de Sítio } \\
\text { Médio }\end{array}$ & $\begin{array}{c}\text { Coeficiente de } \\
\text { Variação do IPM - \% }\end{array}$ \\
\hline 1992 & 3 & 4,75 & 2,34 & 1473 & 23,66 & 18,71 \\
\hline 1993 & 3 & 5,11 & 2,06 & 1232 & 25,79 & 21,51 \\
\hline 1994 & 3 & 4,83 & 2,18 & 1153 & 25,32 & 20,51 \\
\hline 1995 & 7 & 4,87 & 2,75 & 1195 & 24,71 & 19,58 \\
\hline 1996 & 8 & 5,59 & 1,62 & 1213 & 24,57 & 21,29 \\
\hline 1997 & 10 & 6,05 & 2,70 & 1200 & 24,85 & 14,24 \\
\hline 1998 & 10 & 5,20 & 2,59 & 1084 & 24,99 & 11,92 \\
\hline \multicolumn{7}{|c|}{ Guanhães } \\
\hline 1986 & 5 & 4,63 & 3,19 & 1423 & 26,63 & 20,51 \\
\hline 1987 & 5 & 4,60 & 3,80 & 1569 & 26,65 & 26,50 \\
\hline 1989 & 11 & 5,73 & 3,85 & 1561 & 28,16 & 18,52 \\
\hline 1990 & 4 & 5,75 & 2,73 & 1569 & 30,41 & 25,82 \\
\hline 1991 & 15 & 5,91 & 4,39 & 1583 & 29,58 & 18,17 \\
\hline 1992 & 12 & 5,39 & 5,92 & 1579 & 29,68 & 20,61 \\
\hline 1993 & 12 & 5,10 & 4,95 & 1588 & 29,33 & 13,02 \\
\hline 1994 & 22 & 5,20 & 2,71 & 1514 & 28,69 & 19,65 \\
\hline 1995 & 22 & 5,55 & 3,24 & 1470 & 29,01 & 19,91 \\
\hline 1996 & 17 & 5,73 & 3,24 & 1538 & 28,51 & 18,31 \\
\hline 1997 & 24 & 4,86 & 4,73 & 1480 & 29,46 & 16,44 \\
\hline 1998 & 20 & 5,61 & 4,59 & 1484 & 28,68 & 9,70 \\
\hline \multicolumn{7}{|c|}{ Nova Era } \\
\hline 1986 & 3 & 5,67 & 1,69 & 1649,00 & 23,77 & 27,44 \\
\hline 1987 & 2 & 6,00 & 3,25 & 1612,50 & 23,61 & 15,23 \\
\hline 1990 & 5 & 5,20 & 4,52 & 1853,20 & 23,86 & 18,83 \\
\hline 1991 & 6 & 4,61 & 4,74 & 1536,83 & 29,24 & 17,92 \\
\hline 1992 & 11 & 5,70 & 5,24 & 1571,00 & 28,43 & 19,21 \\
\hline 1993 & 7 & 5,05 & 4,26 & 1562,43 & 26,39 & 20,13 \\
\hline 1994 & 15 & 5,65 & 2,75 & 1515,80 & 25,58 & 21,62 \\
\hline 1995 & 27 & 5,19 & 3,56 & 1419,30 & 25,82 & 20,40 \\
\hline 1996 & 25 & 5,93 & 3,28 & 1410,16 & 25,53 & 20,32 \\
\hline 1997 & 19 & 5,71 & 4,19 & 1366,16 & 26,77 & 14,91 \\
\hline 1998 & 10 & 5,41 & 3,84 & 1386,70 & 26,64 & 16,81 \\
\hline
\end{tabular}

Calculou-se o incremento periódico anual (IPA), baseando no intervalo entre duas medições do inventário, conforme metodologia apresentada por Campos e Leite (2002). O incremento periódico mensal (IPM) foi obtido, dividindo-se o IPA pelo número de meses entre as duas mensurações florestais, sendo o IPM contabilizado no ano da última medição.

O índice de local é um indicativo da capacidade produtiva de um local e corresponde à altura dominante média de um povoamento em uma idade específica (idadeíndice). Esses índices foram obtidos para cada talhão, empregando-se o método da curva-guia e o modelo de Schumacher, conforme Campos e Leite (2002), com base na idade-índice de 72 meses. No Quadro 2, apresentase o índice local médio dos lotes avaliado a cada ano.

\section{RESULTADOS E DISCUSSÃO}

A precipitação total anual para Guanhães, Nova Era e Belo Oriente pode ser visualizada na Figura 3. Observou-se que a distribuição anual apresentava comportamento semelhante, nas três regiões. Quanto ao total precipitado, notaram-se valores bem próximos, variando de $1.276 \mathrm{~mm}$ anuais em Nova Era a $1.202 \mathrm{~mm}$ em Belo Oriente (Tabela 1). Nos três locais, o trimestre 
mais chuvoso ocorreu de outubro a dezembro e, em seguida, de janeiro a março; dessa forma, a estação chuvosa ocorre entre os meses de outubro a março (Figura 3). O total precipitado na estação chuvosa representou $87 \%$ do total anual precipitado em Guanhães e Belo Oriente e $84 \%$ em Nova Era.

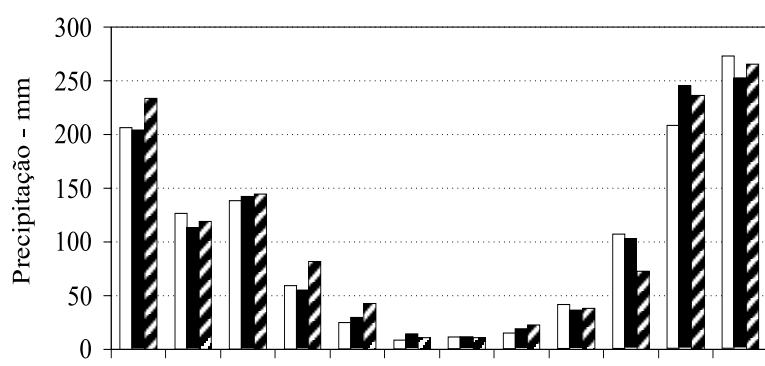

Jan Fev Mar Abr Mai Jun Jul Ago Set Out Nov Dez $\square$ Guanhães Belo Oriente $\square$ Nova Era

Figura 3 - Precipitação anual relativa ao período de 1985 a 1998, em Guanhães, Nova Era e Belo Oriente.

Figure 3-Annual precipitation over the period 1985 - 1998 in Guanhães, Nova Era and Belo Oriente.

$\mathrm{Na}$ Figura 4, apresenta-se, para as três regiões, o total precipitado em cada estação chuvosa referente ao período de 1985 a 1998, bem como sua classificação, obtida por meio da técnica dos quantis. Nas três regiões, observou-se alternância inter-anual de estações chuvosas, com totais abaixo e acima da normal. Não se verificou uma coincidência entre as regiões estudadas, entre anos mais ou menos chuvosos, exceto as estações chuvosas de 1986 a 1987, 1988 a 1989, 1991 a 1992 e 1996 a 1997. Esse comportamento demonstrou que o regime de chuva não era homogêneo nas regiões, ou seja, provavelmente não se verificou um sistema dinâmico atmosférico, que originou as chuvas na macrorregião. No entanto, o ritmo das chuvas é governado regionalmente e relaciona-se com a diferença de relevo das regiões.

Como resultado do balanço hídrico seqüencial, obtiveram-se as deficiências e excedentes hídricos mensais, a variação no armazenamento de água no solo e as evapotranspirações potencial e real de Guanhães, Nova Era e Belo Oriente, durante o período de 1985 a 1998, sendo os dados apresentados na Figura 5. Nessa figura, observa-se que Belo Oriente apresentou os maiores valores de deficiência hídrica e menores valores de excedente hídrico.

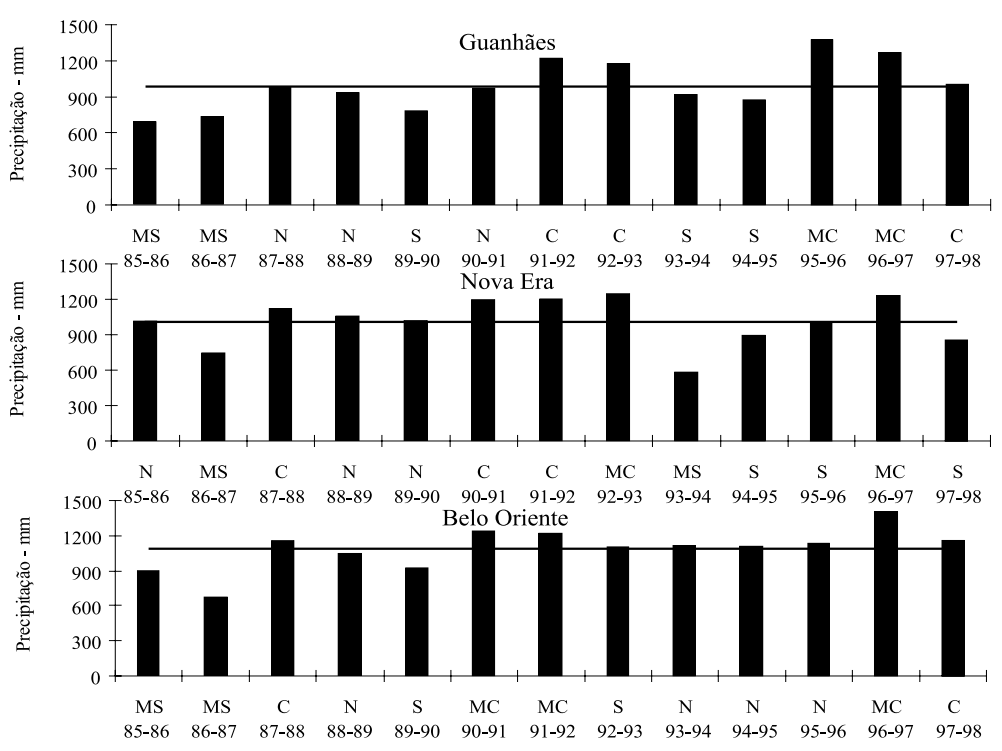

Figura 4 - Precipitação total em cada estação chuvosa, outubro a março, no período de 1985 a 1998, e sua classificação, segundo a técnica dos quantis, para Guanhães, Nova Era e Belo Oriente. A linha cheia representa a média e os símbolos MS, S, N, C e MC, muito seco, seco, normal, chuvoso e muito chuvoso, respectivamente.

Figure 4-Total precipitation in each rainy season, October to March, during the period 1985 - 1998 and its classification according to the quantile technique for Guanhães, Nova Era and Belo Oriente. The full line represents the average, and the symbols $M S, S, N, C$ and $M C$ represent very dry, dry, normal, rainy and very rainy, respectively. 

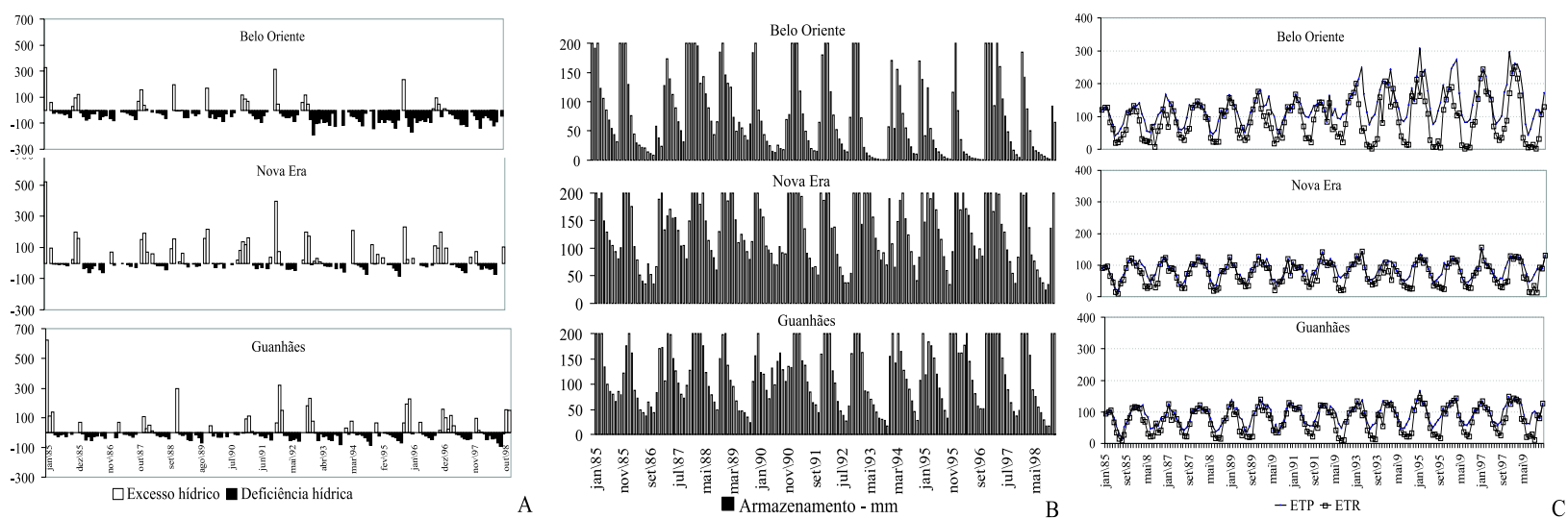

Figura 5 - Variação mensal do excesso hídrico e deficiência hídrica (A), do armazenamento de água no solo (B) e da evapotranspiração potencial (ETP) e real (ETR), C, em mm, no período de 1985 a 1998, para Belo Oriente, Nova Era e Guanhães, Estado de Minas Gerais.

Figure 5 - Monthly variations of the water excess and water deficit (A), soil water storage (B), potential evapotranspiration, ETP, and real evapotranspiration ETR (C) in mm, over the period 1985 - 1998 for Belo Oriente, Nova Era and Guanhães, Minas Gerais State.

A deficiência hídrica média, no período estudado, em Belo Oriente foi de $504 \mathrm{~mm}$ anuais, em Nova Era de 147 mm e em Guanhães de 194 mm anuais. A média total dos excedentes hídricos no período foi de 180 mm em Belo Oriente, 316 mm em Guanhães e 366 mm anuais em Nova Era. A diferença quanto às deficiências hídricas entre as regiões, por si só, não é explicada pela diferença nos totais anuais de chuva, uma vez que praticamente não se verifica diferença entre esses valores. No mesmo sentido, não é possível explicar a maior deficiência hídrica, observada em Belo Oriente, com base na distribuição mensal de chuva (Figura 3), uma vez que a variação sazonal entre locais é bastante semelhante. Assim, o que explica os menores déficits hídricos e maiores excedentes hídricos nas regiões de Nova Era e Guanhães, em comparação com Belo Oriente, é a maior irradiância solar ocorrida nesta última localidade (SOUZA et al., 2004), acrescido do fato de Belo Oriente apresentar a menor altitude e, conseqüentemente, maiores temperaturas em comparação com as outras localidades. Como resultado, tem-se maior disponibilidade energética em Belo Oriente e, conseqüentemente, maior demanda evapotranspirativa, o que pode ser verificado na Figura 5C.

Em conseqüência de a deficiência hídrica ser maior em Belo Oriente, dentre as três regiões, o armazenamento de água no solo (ARM) médio mensal foi também o mais baixo em Belo Oriente (79 mm), enquanto em Guanhães o foi de 119 mm e em Nova Era, de 132 mm.
Os maiores valores de ETP foram observados em Belo Oriente, isto é, $1.593 \mathrm{~mm}$ anuais, seguindo-se Guanhães com 1.103 mm e Nova Era com 1.036 mm. Com relação a ETR, o comportamento é semelhante ao da ETP, com o maior valor em Belo Oriente (1.089 mm anuais), seguido de Guanhães (909 mm) e Nova Era $(890 \mathrm{~mm})$. Quanto à evapotranspiração relativa (ETR/ ETP) média nas três localidades, esta foi de 0,65 ; 0,78; e 0,83 em Belo Oriente, Guanhães e Nova Era, respectivamente. Dessa forma, do ponto de vista hídrico, Nova Era apresenta a maior disponibilidade de água, seguindo-se Guanhães e, finalmente, Belo Oriente.

A Figura 6 ilustra o incremento periódico mensal (IPM), nas idades de 3 a 7 anos, nas três regiões. Observase, nessa figura, que em Belo Oriente o IPM foi o menor entre o das três regiões, seguido de Nova Era e, por último, Guanhães. O IPM médio foi de 2,38 $\mathrm{m}^{3} \mathrm{ha}^{-1} \mathrm{mês}^{-1}$ em Belo Oriente, 3,75 $\mathrm{m}^{3} \mathrm{ha}^{-1} \mathrm{mês}^{-1} \mathrm{em}$ Nova Era e 4,00 $\mathrm{m}^{3} \mathrm{ha}^{-1} \mathrm{mês}^{-1}$ em Guanhães.

Belo Oriente é o local de menor altitude, apresentando as maiores temperaturas (Figura 2) e, consequientemente, a maior demanda evapotranspirativa (Figura 5C). Portanto, apresenta os menores valores de condutância estomática (gs), devido ao maior déficit de pressão de vapor (DPV), observado na região, como pode ser visualizado na Figura 7. Essa figura ilustra a variação da condutância estomática em função da DPV em Belo Oriente e Peçanha (localizada na região 
de Guanhães). Verifica-se, nessa figura, que em Belo Oriente a condutância apresenta redução maior com o aumento do DPV, o que possivelmente esteja relacionado à maior disponibilidade de radiação solar, que também favorece o fechamento estomático. Assim, em Belo Oriente, embora seja verificado maior evapotranspiração, os estômatos tendem a permanecer fechados por mais tempo, ou seja, a transpiração ocorre em taxas mais elevadas. Uma vez que o ganho de $\mathrm{CO}_{2}$ ocorre por difusão, as localidades de Guanhães e Nova Era tendem a fotossintetizar por um tempo maior durante o dia, justificando a maior biossíntese. Dessa forma, a menor condutância estomática e o maior gasto de energia com a respiração, em Belo Oriente, são subsídios para explicar a ocorrência de menor biossíntese nessa região.

Em Belo Oriente, apesar de a precipitação média anual apresentar valor e distribuição anual bem semelhantes àqueles de Guanhães e Nova Era (Figura 2), o IPM foi inferior ao desses dois locais. Em Guanhães o IPM chega a ser $68 \%$ superior ao de Belo Oriente. Em Nova Era, esse índice chega a ser 57\% superior ao de Belo Oriente. Em razão de a variação nos totais de precipitação (Figura 2) ser muito pequena, não é possível explicar os diferentes ganhos de volume entre as três regiões com base nessa variável. No entanto, Stape e Gomes (1996), estudando a influência dos estresses hídricos e nutricionais no crescimento de plantios de eucaliptos, no Nordeste do Brasil, obtiveram incrementos anuais (IPA) superiores nos locais com maior precipitação, em solos Podzólicos e Latossólicos. Provavelmente, isso ocorreu devido ao fato de a variabilidade de precipitação nos locais estudados ter sido grande (800 a $1.700 \mathrm{~mm}$ anuais), além da baixa variabilidade de altitude desses locais (60 a $330 \mathrm{~m}$ ), sendo que a altitude influencia, diretamente, a temperatura do local e, por consequiência, a demanda evaporativa. Assim, a chuva e sua distribuição sazonal não pode, por si só, explicar a diferença em produtividade florestal nas diferentes regiões, conforme já apontava Billings (1952), com relação à complexidade de fatores que interferem na produtividade vegetal.

Comparando o IPM obtido (Figura 6) com total precipitado em cada estação chuvosa (Figura 4), verificou-se que o IPM foi menor nos anos precedidos de estações chuvosas, classificadas como seca (S) ou muito seca (MS). Tal fato é mais pronunciado em Guanhães e Nova Era.

Em Nova Era, as estações chuvosas de 1993/1994 e de 1994/1995, classificadas como MS e S, respectivamente, apresentaram IPM de 2,75 $\mathrm{m}^{3} \mathrm{ha}^{-1} \mathrm{mês}^{-1} \mathrm{e}$ 3,56 $\mathrm{m}^{3} \mathrm{ha}^{-1} \mathrm{mês}^{-1}$ nos anos de 1994 e 1995, respectivamente, sendo esses um dos menores valores obtidos nessa localidade. Em Guanhães, o comportamento foi semelhante, sendo os menores valores de IPM obtidos nos anos precedidos por estação chuvosa S ou MS, exceto o ano de 1996, que teve um dos mais baixos IPM $\left(3,24 \mathrm{~m}^{3} \mathrm{ha}^{-1} \mathrm{mês}^{-1}\right)$ e estação chuvosa precedente MC, sendo esta a de maior precipitação acumulada $(1.366 \mathrm{~mm})$. Isso ocorreu, provavelmente, porque as árvores não haviam se recuperado do período seco, durante as duas estações chuvosas anteriores (classificadas como seca), e, ou, o alto excedente hídrico tenha influenciado negativamente (Figura 5A).

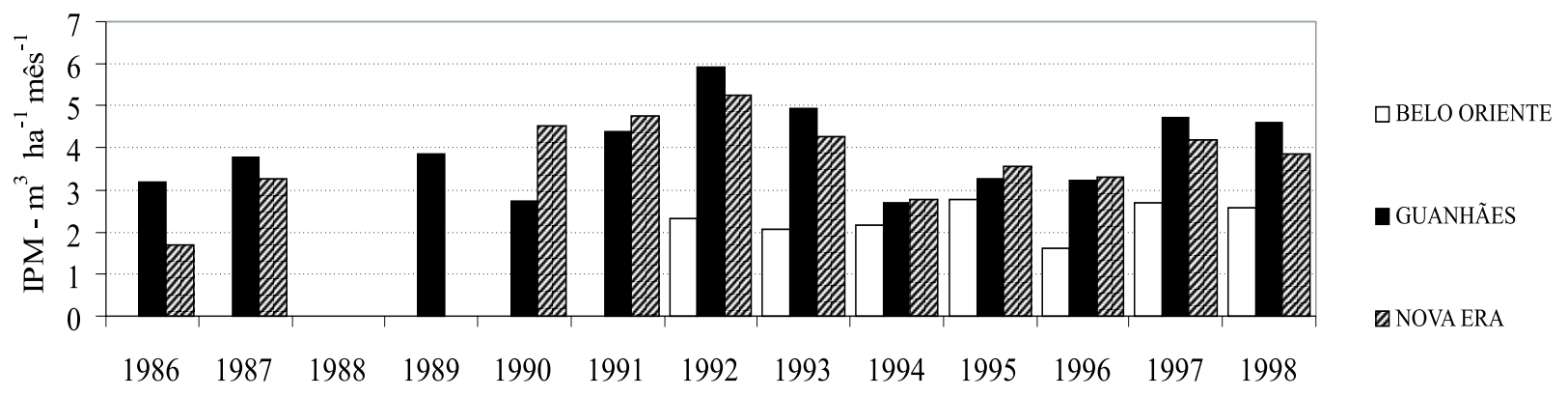

Figura 6 - Incremento periódico mensal (IPM), em m ${ }^{3} \mathrm{ha}^{-1} \mathrm{mês}^{-1}$, nas árvores com idades entre 3 e 7 anos, nas regiões de Guanhães, Nova Era e Belo Oriente, MG.

Figure 6 - Monthly periodic increase (IPM), $\mathrm{m}^{3} h \mathrm{a}^{-1} \mathrm{mo}^{-1}$, for trees aged 3 - 7 years in Guanhães, Nova Era and Belo Oriente, Minas Gerais State.

R. Árvore, Viçosa-MG, v.30, n.3, p.399-410, 2006

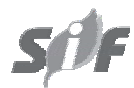



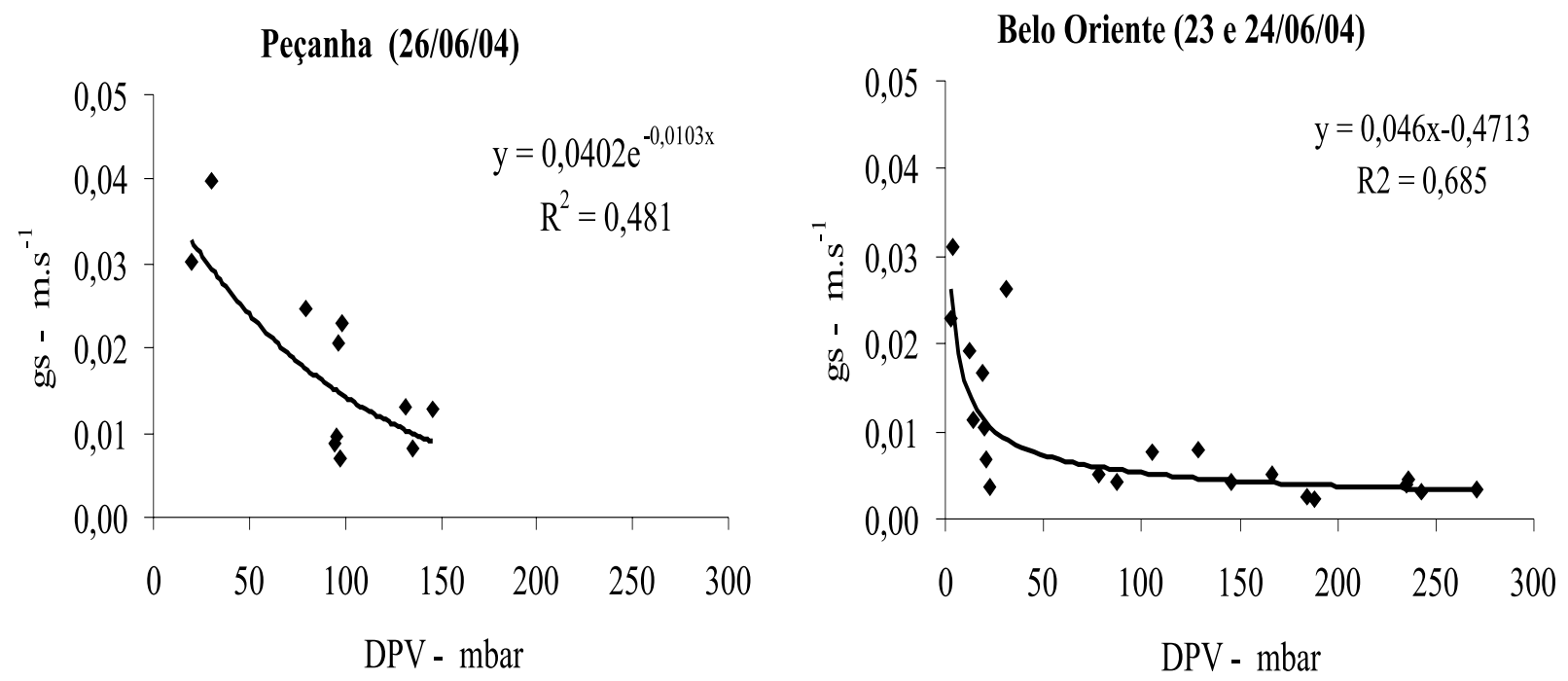

Figura 7 - Condutância estomática (gs), m.s.s , e déficit de pressão de vapor (DPV), mbar, em duas regiões da CENIBRA. Figure 7 - Stomatic conductance ( $g s), m . s^{-1}$, vapor pressure deficit (VPD), mbar, in two CENIBRA regions.

A produtividade foi superior nos anos precedidos de estação chuvosa, classificada como chuvosa (C) ou muito chuvosa (MC), ou seja, os valores de IPM foram maiores (Figuras 4 e 6). Em Guanhães, os maiores valores de IPM foram obtidos nos anos de $1992\left(5,92 \mathrm{~m}^{3} \mathrm{ha}^{-1} \mathrm{mês}^{-1}\right), 1993$ (4,95 m ha ${ }^{-1}$ mês $\left.^{-1}\right)$ e $1997\left(4,73 \mathrm{~m}^{3} \mathrm{ha}^{-1} \mathrm{mês}^{-1}\right)$, os quais foram precedidos de estações chuvosas classificadas como C (1991/1992 e 1992/1993) e MC (1996/1997). Em Nova Era, os maiores valores de IPM foram obtidos nos anos de $1992\left(5,24 \mathrm{~m}^{3} \mathrm{ha}^{-1} \mathrm{mês}^{-1}\right)$, em $1991\left(4,74 \mathrm{~m}^{3} \mathrm{ha}^{-1} \mathrm{mês}^{-1}\right) \mathrm{e}$ $1993\left(4,26 \mathrm{~m}^{3} \mathrm{ha}^{-1} \mathrm{mês}^{-1}\right)$, anos esses precedidos de estações chuvosas classificadas como C (1991/1992 e 1990/1991) e MC (1992/1993). Em Belo Oriente, esse fato não foi tão evidente.

Ao relacionar o total precipitado na estação chuvosa finalizada em cada ano com o incremento periódico mensal (IPM), nas regiões de Nova Era e Guanhães (Figura 8), verificou-se aumento na precipitação na estação chuvosa (PEC) e nos IPM entre 1986 e 1992, nas duas regiões. No período de 1992 a 1995, observouse decréscimo nas PEC e IPM em Nova Era e Guanhães. Correlacionando os IPM e as PEC relativos aos dois períodos e das duas regiões, obteve-se uma relação linear. Os coeficientes das equações, juntamente com os coeficientes de determinação $\left(r^{2}\right)$, são apresentados no Quadro 3.
Quanto ao período de 1986 a 1992, o IPM respondeu positivamente à maior disponibilidade de água no solo (Figura 8), conforme as equações obtidas (Quadro 3). Nesse período, o ganho de volume médio foi de 0,51 $\mathrm{m}^{3} \mathrm{ha}^{-1} \mathrm{mês}^{-1}$ em Guanhães e de $0,38 \mathrm{~m}^{3} \mathrm{ha}^{-1} \mathrm{mês}^{-1} \mathrm{em}$ Nova Era, para um aumento correspondente de $100 \mathrm{~mm}$ na PEC. No período de redução anual da PEC (1992 a 1995), entretanto, obteve-se uma redução de volume de 0,98 $\mathrm{m}^{3} \mathrm{ha}^{-1} \mathrm{mês}^{-1}$ em Guanhães e de $0,30 \mathrm{~m}^{3} \mathrm{ha}^{-1} \mathrm{mês}^{-1} \mathrm{em}$ Nova Era, para uma diminuição de $100 \mathrm{~mm}$ na PEC. Dessa feita, observou-se que, nas duas regiões, a taxa de aumento no IPM, ocasionado pelo aumento anual na PEC, é diferente da taxa de redução no IPM, proporcionado pela diminuição anual da PEC, sendo essa diferença maior em Guanhães.

Quanto ao potencial produtivo de cada local, verificou-se que Belo Oriente apresentou o menor índice de local, com valor médio de todos os lotes envolvidos no estudo igual a 24,8 (com um coeficiente de variação, CV, de 4,6\%); em Nova Era, esse índice foi de 26,2 (CV de 9,9\%) e em Guanhães, de 29,0 (CV de 13,4\%). É claro que o índice de local, bem como a produtividade desse local, reflete as condições do meio ambiente, como um todo, e não somente os efeitos do clima, sofrendo a influência de outros fatores ambientais, ou seja, fisiográficos, edáficos e bióticos.

R. Árvore, Viçosa-MG, v.30, n.3, p.399-410, 2006 


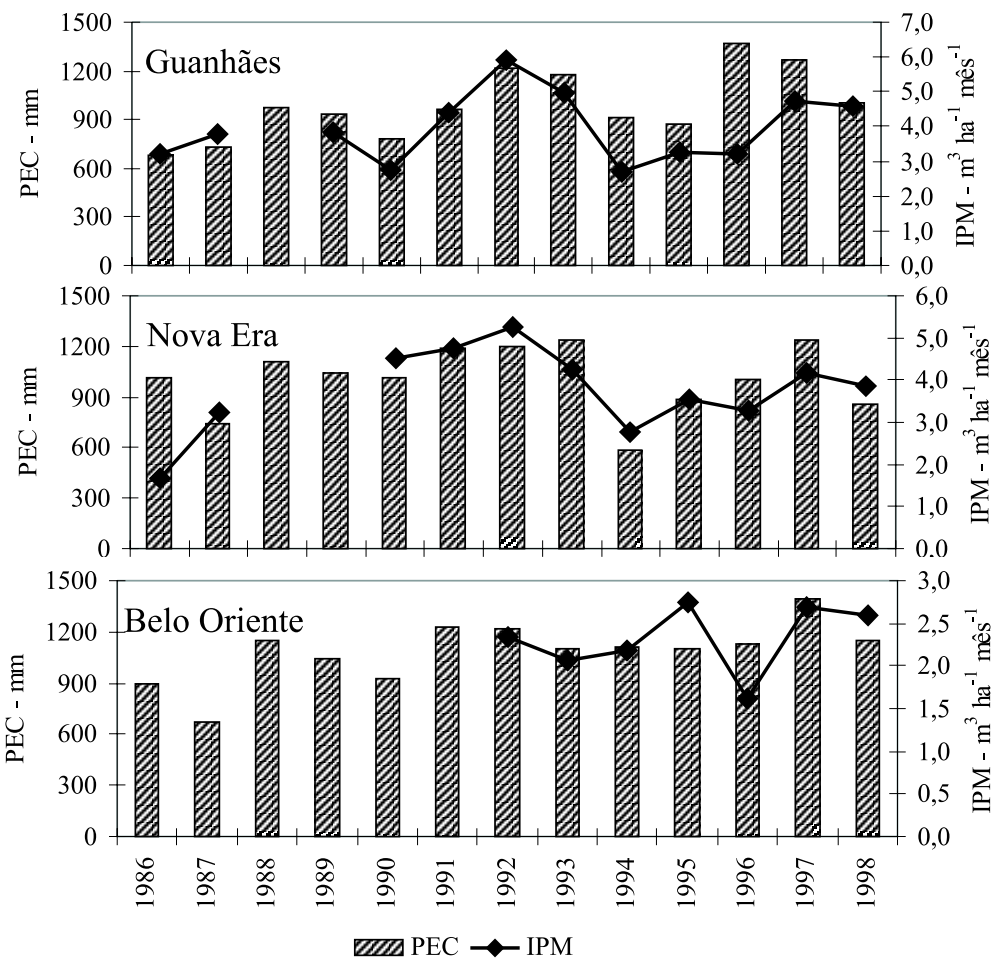

Figura 8 - Precipitação da estação chuvosa finalizada em cada ano (PEC), em mm, e incremento periódico mensal (IPM), $\mathrm{em} \mathrm{m}^{3} \cdot \mathrm{ha}^{-1}$. ês $^{-1}$, nas regiões de Guanhães, Nova Era e Belo Oriente, Estado de Minas Gerias.

Figure 8 - Total precipitation in the rainy season finished at every year (RSP PEC), in mm, and monthly periodic increment (MPI IPM), $m^{3} \cdot h a^{-1} . m^{-1}$, in Guanhães, Nova Era and Belo Oriente regions, Minas Gerais State.

Quadro 3 - Coeficientes angular e linear e coeficiente de determinação $\left(\mathrm{r}^{2}\right)$ obtidos durante os períodos de 1986 a 1992 e de 1992 a 1995 , em Nova Era e Guanhães

Table 3 - Angular and linear coefficients and determination coefficient $\left(r^{2}\right)$ obtained during the periods 1986 - 1992 and 1992 - 1995, in Nova Era and Guanhães regions

\begin{tabular}{lllllrl}
\hline & & & $\begin{array}{c}\text { Coeficiente } \\
\text { Angular }\end{array}$ & $\begin{array}{c}\text { Coeficiente } \\
\text { Linear }\end{array}$ & $\mathrm{r}^{2}$ \\
\hline Nova Era & 1986 a 1992 & 0,0038 & 0,4957 & 0,93 \\
& 1992 a & 1995 & 0,0030 & 1,0186 & 0,80 \\
Guanhães & 1986 a 1992 & 0,0051 & $-0,4829$ & 0,81 \\
& 1992 a & 1995 & 0,0098 & $-6,2301$ & 0,97 \\
\hline
\end{tabular}

\section{CONCLUSÕES}

O incremento periódico mensal (IPM) de Belo Oriente foi inferior ao dos outros dois locais, ou seja, em Guanhães foi cerca de $68 \%$ superior ao de Belo Oriente, enquanto o de Nova Era, $57 \%$ superior ao de Belo Oriente. Como a variação da precipitação anual nas três regiões é muito pequena, ela não possibilita explicar os diferentes ganhos de volume entre as três regiões estudadas.

Belo Oriente apresentou as maiores temperaturas, maiores valores de deficiência hídrica e menores valores de excedentes hídricos, assim como os mais baixos níveis de armazenamento de água no solo. Nova Era teve as temperaturas mais amenas, bem como os maiores excedentes hídricos, as menores deficiências hídricas e os mais altos níveis de armazenamento de água no solo.

A produtividade de madeira foi influenciada pelo total precipitado durante a estação chuvosa, sendo os menores valores de incremento periódico mensal (IPM) observados nos anos precedidos de estações chuvosas, classificadas como secas (S) ou muito secas (MS), enquanto os maiores valores de IPM foram verificados nos anos precedidos de estação chuvosa 
classificada como chuvosa (C) ou muito chuvosa (MC), fato esse mais pronunciado em Guanhães e Nova Era.

Verificou-se correlação positiva entre o total precipitado durante a estação chuvosa finalizada em cada ano (PEC) e o ganho de volume. A correlação entre o IPM com os períodos de aumento na PEC (1986 a 1992) e de diminuição na PEC (1992 a 1996) em Guanhães e Nova Era apresentou um $\mathrm{r}^{2}$ acima de $80 \%$. Um incremento de $100 \mathrm{~mm}$ na PEC significou um ganho de volume médio de $0,51 \mathrm{~m}^{3} \mathrm{ha}^{-1} \mathrm{mês}^{-1}$ em Guanhães e de $0,38 \mathrm{~m}^{3} \mathrm{ha}^{-1} \mathrm{mês}^{-1}$ em Nova Era. Entretanto, no período de redução anual da PEC (1992 a 1995), a diminuição de volume foi de $0,98 \mathrm{~m}^{3} \mathrm{ha}^{-1} \mathrm{mês}^{-1}$ em Guanhães e de $0,30 \mathrm{~m}^{3} \mathrm{ha}^{-1} \mathrm{mês}^{-1}$ em Nova Era, para uma diminuição de $100 \mathrm{~mm}$ na PEC.

Do ponto de vista climático, Guanhães apresentou o maior índice local médio, bem como a maior produtividade média, seguida de Nova Era e, por último, Belo Oriente, sendo esta localidade bem aquém da primeira.

\section{AGRADECIMENTOS}

À Coordenação de Aperfeiçoamento de Pessoal de Nível Superior (CAPES), pelo financiamento desta pesquisa; e à Empresa Florestal Celulose Nipo-Brasileira (CENIBRA), pelo fornecimento dos dados.

\section{REFERÊNCIAS BIBLIOGRÁFICAS}

BERGH, J.; MCCMURTRIE, R.E.; LINDER, S. Climatic factors controlling the productivity of Norway spruce: A model-based analysis.

Forest Ecology and Management, n.110, p.127-139, 1998.

BILLINGS, W.D. The environmental complex in relation to plant growth and distribution. The Quarterly Review of Biology, v.27, n.3, p.251-264, 1952.

CAMPOS, J.C.C. Principais fatores do meio que afetam o crescimento das árvores. Floresta, n.3, p.45-52, 1970 .

CAMPOS, J.C.C.; LEITE, H.G. Mensuração florestal: perguntas e respostas. Viçosa - MG: Universidade Federal de Viçosa, 2002. 407p.
DOORENBOS, J.; KASSAM, A.H. Yield response to water. Rome: FAO, 1979. 306p. (Irrigation and Drainage, 33).

MAESTRI, R. Modelo de crescimento e produção para povoamentos clonais de eucalyptus grandis considerando variáveis ambientais. 2003. 143f. Dissertação (Doutorado em Engenharia Florestal) - Universidade Federal do Paraná, Curitiba, 2003.

NEVES, J.C.L. Produção e partição de biomassa, aspectos nutricionais e hídricos em plantios clonais de eucalipto na região litorânea do Espírito Santo. 2000. 191f. Dissertação (Doutorado em Ciências Florestais) Universidade Estadual do Norte Fluminense, Rio de Janeiro, 2000.

PEREIRA, A,R.; ANGELOCCI, L.R.; SENTELHAS, P.C. Agrometeorologia fundamentos e aplicações práticas. Guaíba - RS: Agropecuária, 2002.478p.

PINKAYAN, S. Conditional probabilities of occurrence of wed and dry years over a large continental area. Boulder-CO: Colorado State University, 1966. (Hidrology Papers, 12).

PIRES O'BRIEN, M. J. Ecologia e modelamento de florestas tropicias. Belém-PA: FCAP, 1995. 400p.

SACRAMENTO NETO, O. B. Balanço hídrico em plantios jovens de eucalipto na região de Belo Oriente-MG. 2001. $77 \mathrm{f}$. Dissertação (Mestrado em Meteorologia Agrícola) - Universidade Federal de Viçosa, Viçosa, 2001.

SANDS, R.; MULLIGAN, D. R. Water and nutrient dynamics and tree growth. Forest Ecology and Management, n.30, p.91-111, 1990.

SOARES, C.P.B. Um modelo para o gerenciamento da produção de madeira em plantios comerciais de eucalipto. 1999. $71 \mathrm{f}$. Dissertação (Doutorado em Ciência Florestal) - Universidade Federal de Viçosa, Viçosa, 1999.

R. Árvore, Viçosa-MG, v.30, n.3, p.399-410, 2006 
STAPE, J.L.; GOMES, A.N. Influência dos estresses hídricos e nutricionais no crescimento de plantios de eucaliptos no nordeste do Brasil. In: CONGRESSO LATINO AMERICANO DE CIÊNCIA DO SOLO, 10., 1996, Águas de Lindóia. Anais... Águas de Líndoia: 1996. CD-ROM.

STAPE, J.L. Production ecology of clonal eucalyptus plantation in northeastern Brazil. 2002. 225f. Tese (Pós Doutorado em Ciência Florestal) - Universidade do Colorado, Fort Collins, 2002.

SOUZA, M.J.H.; RIBEIRO, A.; LEITE, F.P. Balanço Hídrico e Caracterização Climática de Guanhães, Nova Era e Rio Doce. In: CONGRESSO BRASILEIRO DE AGROMETEOROLOGIA, 13., 2003, Santa Maria.

Anais... Santa Maria - RS: Sociedade Brasileira de Agrometeorologia, 2003. v. 1. p. 131-132.

SOUZA, M.J.H.; RIBEIRO, A.; LEITE, F.P.

Variação sazonal e diurna da irradiância solar global em cinco localidades do Vale do Rio Doce - MG. In: CONGRESSO BRASILEIRO DE METEOROLOGIA, 12., 2004, Fortaleza. Anais.. Fortaleza - CE: Sociedade Brasileira de Meteorologia, 2004. CD-ROM.
THORNTHWAITE, C.W.; MATHER, J.R. The water balance. Publication in climatology. v. 8, n. 1, 104 p, 1955.

VOSE, J. M.; SWANK, W.T. Effect of long-term drought on the hydrology and growth of a white pine plantation in the southern Appalachians. Forest Ecology and Management, n. 64, p. 25-39, 1994.

WOOLLONS, R.C.; SNOWDON, P.; MITCHELL, N.C. Augmenting empirical stans projections with edaphic and climatic variable. Forest Ecology and Management, n. 98, p. 267-275, 1997.

XAVIER, T.M.B.S. Tempo de chuva: estudos climáticos e de previsão para o ceará e nordeste setentrional. Fortaleza -CE: ABC, 2001.476p.

YET, H.Y.; WENSEL, L.C.; TURNBLOM, E.C. An objective approach for classifying precipitation patterns to study climatic effects on tree growth. Forest Ecology and Management, n. 139, p. 41-50, 2000. 